\title{
FIRST CHOICE OF ACCUS
}

\section{Dear Reader,}

when it comes to selecting traction batteries - or more precisely their cells the dice have been cast. Car makers have decided which cell designs and chemical formulations are to be used in the first generation of their electric drive systems. It is now up to cell manufacturers to supply the cells reliably and in larger quantities. That is not always possible, as it is production techniques that ultimately determine the rules of the game, and only few manufacturers fully understand them.

Volkswagen, Ford and Toyota have a good set of cards. They have gone for cells from Panasonic, and have therefore opted for a stable, prismatic cell design. Although this type is heavier and bigger than the competing pouch cell design, many experts are sceptical about pouch cells, in spite of their better package. There is a ongoing debate about whether this design is the reason why this type of cell is inferior in terms of durability, as is the case at Nissan. In this OEM's batteries, maximum capacity is already down to just $80 \%$ after two years instead of the required ten.

The trump card may well be held by the above-mentioned OEMs and other manufacturers who favour electrodes made of nickel manganese cobalt, even though these cells have a lower output than lithium iron phosphate (LFP) cells. So is VW buying second-rate cells? No.

They prefer to play it safe. They foresee problems with LFP cells: although being intrinsically safe, their mass production is challenging. Even the smallest metal particles in the films constantly cause short circuits. The US-American pioneer A123 knows this from personal experience, as do some Chinese battery manufacturers.
But this is no cause for pessimism. It is merely a snapshot of the current situation - in the context of the recent history of the electric car, both research and development are still in the early stages. Among the pioneers are those material scientists and production engineers who present their forwardlooking approaches in this issue of ATZelektronik. They give a good insight into the maturity of national activities.

Many questions still remain unanswered. For example, how well developed Germany is as a location for cell production. Some insiders claim that it will take more than ten years to build up the necessary expertise. Others say that we are hot on the heels of Panasonic.

But how far ahead are the Japanese in reality? Some of them do not even apply for a patent for their systems so as not to show their cards. OEM customers buy a black box - and it works.

Kind regards,

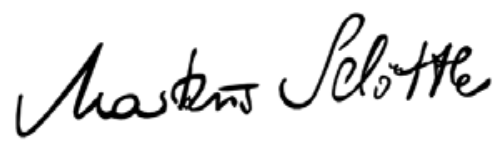

MARKUS SCHÖTTLE, Vice-Editor in Chief Wiesbaden, 24 April 2013

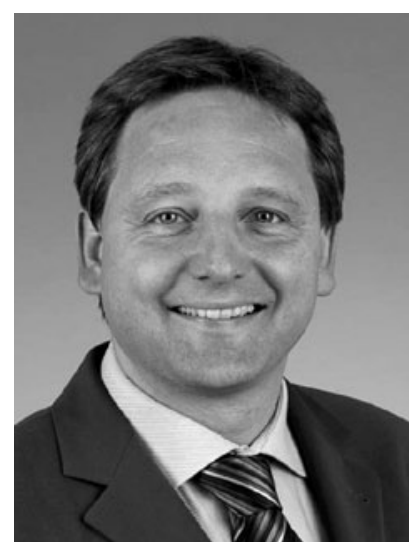

